\title{
APPLICATION OF TWO-PARAMETER FATIGUE CHARACTERSITICS IN FATIGUE PERSISTENCE CALCULATIONS OF STRUCTURAL COMPONENTS UNDER CONDITIONS OF A BROAD SPECTRUM OF LOADS
}

\begin{abstract}
The paper presents an original method of calculation of the fatigue persistence based on the adoption of the load spectrum in the form of a correlation table, two-parameter fatigue characteristics and the linear hypothesis of fatigue damage summation. The calculation results by the proposed method were compared with the results of fatigue tests programmed for node-seal construction. On the basis of a comparative analysis of the test results and calculations conclusions regarding the usefulness of the proposed method to evaluate the fatigue persistence of components have been reached.
\end{abstract}

Keywords: fatigue persistence, linear hypothesis of fatigue damage summation, fatigue tests

\section{INTRODUCTION}

Research and analysis of the two-parameter fatigue characteristics carried out in recent years [1] enabled the development of new, effective methods of calculation of the fatigue persistence of components subjected to loads with a wide spectrum of operating conditions.

Loads of this type are loads typical for structural components of means of transport (motor vehicles, airplanes, etc.) including ocean engineering objects, e.g. offshore drilling platforms [2] and shipbuilding [3] and [4]. In [3] the basic assumptions of methods of calculation of the fatigue persistence of ship structure elements have been given. The assumptions show that in these calculations should take into account: the cyclic property (fatigue) of the analysed structural element designated under load conditions of constant amplitude [1], variable loads in the form of a load spectrum (the set of cycles with variable values, maximum and minimum or variable amplitudes and average values of cycles) [5] and the corresponding hypothesis of summing damage [6]. In [4] are examples of calculations of elements of ship structures.

Development of load spectra requires a suitable method of counting cycles [7], which is also described in the monograph [8]. Dedicated cycles of duty operation of a random broad-spectrum is conveniently summarized in a table of coordinates: $S_{\text {mini }}, S_{\text {maxi }}$ [3], or $S_{a i}, S_{m i}$ [5]. In this paper the second embodiment has been used since it is compatible with the system adopted in the description of two-parameter fatigue characteristics [1]. 
The complexity of the material properties, the structure and geometry of the bonded components, which include ship structures [9] and [10] causes the cyclical properties are designated on the so-called elementary nodes and not on core materials, as is done in the elements of machines with the uniform structure of the material [8]. This type of method to describe the cyclic properties has been adopted by the International Institute of Welding (IIW) publishing a catalogue of $S$ - $N$ curves (Wöhler diagrams) for welded joints [11], also described in [12].

These data were used in the calculation according to the original method based on the adoption of the load spectrum in the form of a table of correlation $\left(S_{m i}, S_{a i}\right)$ [5], a modified two-parameter characteristics of fatigue IM model (model I modified) [13] and the linear hypothesis summation of fatigue damage of Palmgren-Miner [6].

The aim of the study is a comparative analysis of the results of calculation of the fatigue persistence of the proposed method with the results of experimental studies on the example of node-seal construction.

The work includes: formulation of the problem, a description of the fatigue properties of the node, an analysis of operational loads and description of the spectrum load persistence calculations and comparative analysis of the calculation results and programmable fatigue tests.

\section{FORMULATION OF THE PROBLEM}

According to the linear hypothesis of summation of fatigue damage by Palmgren-Miner, the damage caused by one cycle of parameters $S_{a i}, S_{m j}$ is:

$$
D_{1(i, j)}=\frac{1}{N_{i j}\left(S_{a i}, S_{m j}\right)}
$$

where:

$N_{i j}\left(S_{a i} S_{m j}\right)$ - is the number of cycles for fatigue crack growth under cunstant amplitude and sunusoidal load parameters $S_{a i} S_{m j}$

For random loads with a wide spectrum, the basic hypothesis of linear form is given by:

$$
\sum_{i=1}^{k} \sum_{j=1}^{l} \frac{n_{i j}}{N_{i j}}=1
$$

where:

$i=1,2, \ldots, k$ - number of amplitude level of stress cycle $S_{a i}$,

$j=1,2, \ldots, l-$ the number of levels of the average stress cycle $S_{m j}$

$n_{i j}$ - number of sinusoidal load cycles in a spectrum with parameters $S_{a i} S_{m j}$

$N_{i j}$ - number of sinusoidal cycles of constant amplitude $S_{a i}$ and mean value $S_{m j}$ till fatigue crack.

Introducing a frequency of cycles with defined parameters in the stress spectrum

$$
\alpha_{i j}=\frac{n_{0 i j}}{n_{0}}=\frac{n_{c i j}}{n_{c}}
$$

where:

$n_{0 i j}$ - the number of cycles in the load spectrum with parameters $S_{a i} S_{m j}$

$n_{0}$ - the total number of cycles in the load spectrum

$$
n_{0}=\sum_{i=1}^{k} \sum_{j=1}^{l} n_{0 i j},
$$

$n_{c i j}-$ number of programmed load cycles with parameters $S_{a i} S_{m i}$, till fatigue crack,

$n_{c}$ - the total number of programmed load cycles till fatigue crack - fatigue persistence.

one gets:

$$
n_{c}=\frac{1}{\sum_{i=1}^{k} \sum_{j=1}^{l} \frac{\alpha_{i j}}{N_{i j}}}
$$

$N_{i j}$ is determined from the two-parameter fatigue characteristics.

\section{RESEARCH DESCRIPTION}

\section{RESEARCH OBJECT}

For calculations and tests of the fatigue persistence a soldered construction node was selected as shown in Fig. 1.

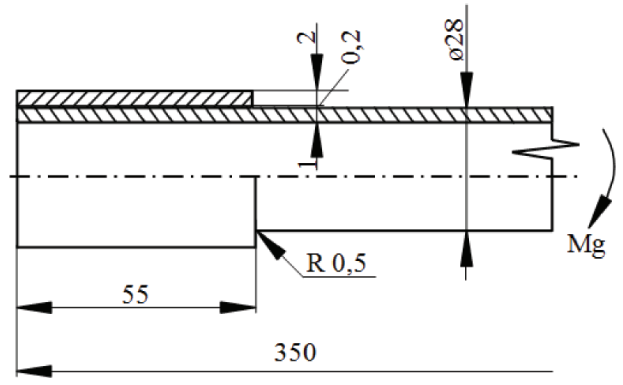

Fig. 1.The construction node made of steel pipe welding

Construction node made of steel pipes (10BX steel) of the following chemical composition: $0,13 \mathrm{C},(0,4 \div 0,6) \mathrm{Mn}$, maximum: 0,003 Si, 0,004 P and 0,0045 S, connected with a LM63 solder. The tensile strength of the pipe $\mathrm{R}_{\mathrm{m}}=363 \mathrm{MPa}$, the yield strength $\mathrm{R}_{0,2}=310 \mathrm{MPa}$.

\section{SERVICE LOADS}

Part of the stress graph in the structural element measured by the strain gauge in service, and basic parameter estimates and the statistical functions shown in Fig. 2. 


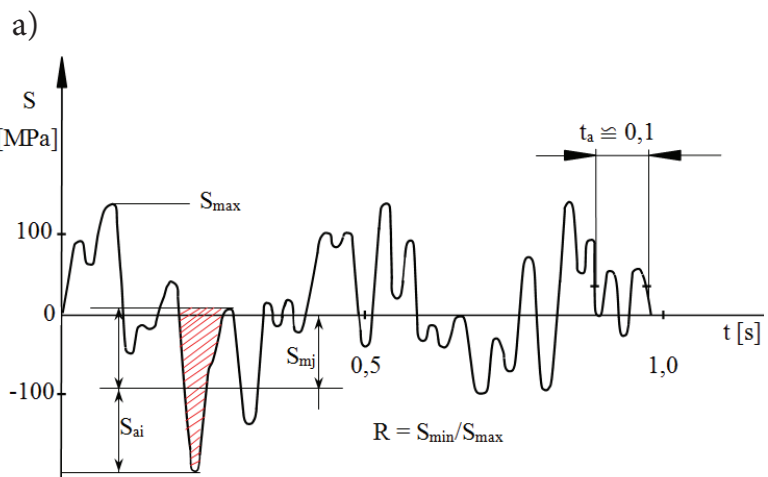

b)
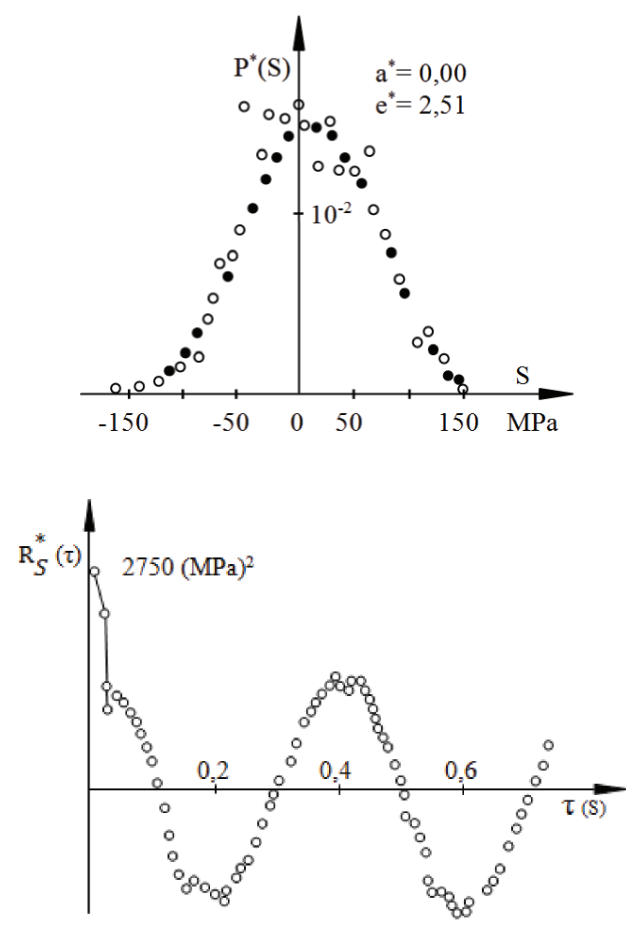

c)

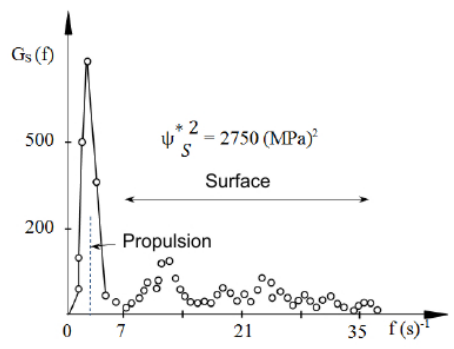

d)

Fig. 2.Service stresses in the construction node: $a$ - part of the chart, $b-$ probability density function, $c$-autocorrelation function, $d$ - the function of spectral density power

From the statistical functions shown in fig. 2 it is clear that the analysed load is the realization of a stochastic process with a broad spectrum and complex structure. The component load with a frequency of about $3,5 \mathrm{~Hz}$ arises from the impact of the user on the drive system and a wide frequency rang eis applied resulting from the impact of road surface irregularities.

The analysis of methods for the development of stress spectrum described in [5] and [8] it is clear that in this case, from among the known methods of counting cycles, the following methods are recommended: counting complete cycles (full cycles counting method), and the method of envelope (rain-flow counting method). In this work, to develop a spectrum of stress in a table of correlation in the system of relative values $S_{a i} / S_{\max } S_{\text {mj }} / S_{\max }$ the method of full cycles has been selected. The data on stress spectrum are shown in Table 1 . The fields of Table 1 include the relative value of numbers of cycles $\alpha_{i j}=n_{0 i j} / n_{0}$. The table field is divided into four fields, depending on the range of variation of the asymmetry factor cycles:

1) $0<R<1,0$;2) $-1,0 \leq R \leq 0$; 3) $-\infty<R<-1,0$; 4) $1<R<+\infty$. Tab. 1. The spectrum of the stress of the structural element $\alpha_{i j} \cdot 10^{3}$

\begin{tabular}{|c|c|c|c|c|c|c|c|c|c|c|}
\hline \multicolumn{2}{|c|}{$S_{a i} S_{\max }$} & 0,8 & 0,7 & 0,6 & 0,5 & 0,4 & 0,3 & 0,2 & 0,1 & \multirow[b]{2}{*}{$\alpha_{1}$} \\
\hline$S_{2} / S$ & & 1 & 2 & & 4 & 5 & 6 & 7 & & \\
\hline 0,4 & 1 & & & 2 & & 4,33 & & 21,65 & (1) & 26 \\
\hline 0,3 & 2 & & & & & 8,66 & 8,66 & 65 & 47,62 & 129,97 \\
\hline 0,2 & 3 & 8,66 & & 4,33 & 4,33 & 4,33 & 47,62 & 90,91 & & 203,46 \\
\hline 0,1 & 4 & & 13 & 17,32 & 30,30 & 34,63 & 17,32 & 65 & 47,62 & 225,11 \\
\hline 0 & 5 & & & 8,66 & 34,63 & 26 & 21,65 & 90,91 & 21,65 & 203,46 \\
\hline$-0,1$ & 6 & 4,33 & & 4,33 & & 8,66 & 8,66 & 56,28 & 26 & 108,23 \\
\hline$-0,2$ & 7 & & & & & 4,33 & 8,66 & 26 & 21,65 & 60,6 \\
\hline$-0,3$ & 8 & & & (3) & & & 8,66 & 13 & 21,65 & 43,29 \\
\hline$-0,4$ & 9 & & & & & & & & & \\
\hline$a_{k}$ & & 13 & 13 & 34,63 & 69,26 & 90,91 & 121,2 & 428,5 & 229,4 & 1000 \\
\hline
\end{tabular}

\section{CYCLIC PROPERTIES OF THE RESEARCH OBJECT}

The determination of fatigue characteristics of twoparameter model by IM requires the designation of Wöhler charts $\left(S_{a i}-N\right)$ for the swinging load $(R=-1,0)$ and the variable unilateral load $(R=0)$. These charts are shown in Fig. 3 .

a)

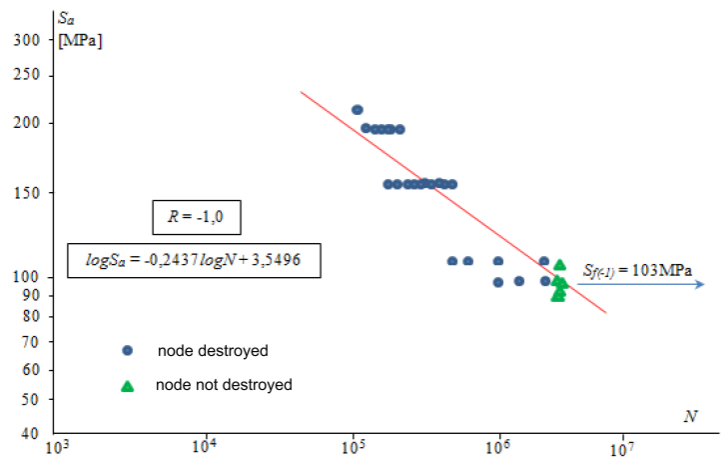


b)

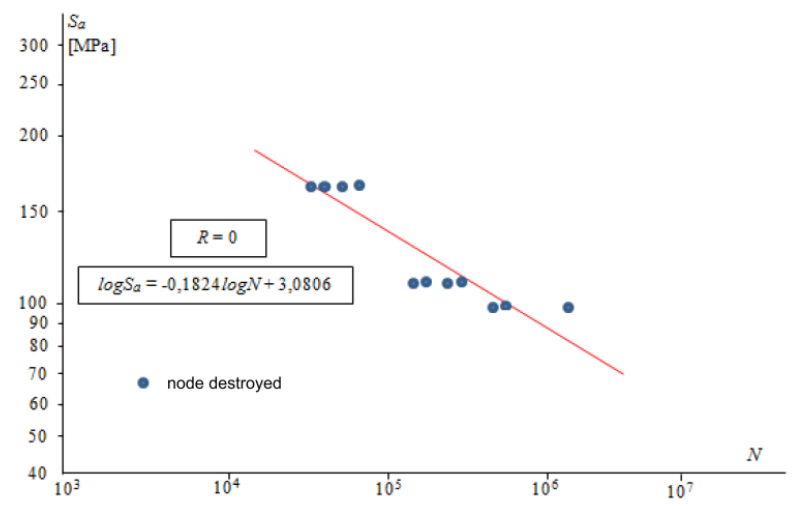

Fig. 3. Wöhler fatigue charts: a) for $R=-1,0, b$ ) for $R=0$ These charts are described by formulas:

$$
\log S_{a}=-\frac{1}{m_{0}} \log N+c_{0}
$$

and

$$
\log S_{a}=-\frac{1}{m} \log N+c
$$

On the basis of formulas (5) and (6) a two-parameter fatigue characteristic has been determined in the form: - for area 1

$$
\begin{gathered}
N_{i j}=N_{0}\left[\frac{S_{f(-1)} \cdot\left(R_{m}+S_{a i}-S_{m j}\right)}{S_{a i} \cdot R_{m} \cdot\left(1+\psi_{N}\right)}\right]^{m_{0}} \\
\text { for } 0<R<1
\end{gathered}
$$

- for area 2

$$
N_{i j}=N_{0} \frac{S_{f(-1)}^{m_{0}}}{\left(S_{a i}+\psi_{N} \cdot S_{m j}\right)^{m_{0}}}
$$

- for area 3

- for area 4

$$
N_{i j}=N_{0} \frac{S_{f(-1)}^{m_{0}}}{\left(S_{a i}-\psi_{N} \cdot S_{m j}\right)^{m_{0}}}
$$

$$
\begin{gathered}
N_{i j}=N_{0}\left[\frac{S_{f(-1)} \cdot\left(R_{m}+S_{a i}+S_{m j}\right)}{S_{a i} \cdot R_{m} \cdot\left(1+\psi_{N}\right)}\right]^{m_{0}} \\
\text { for } 1<R<+\infty
\end{gathered}
$$

where $\psi_{N}$ is the coefficient of sensitivity to the asymmetry of the cycle $R$.

The chart of two-parameter fatigue characteristics of the construction element being analyzed and of selected lines of stability constants $N=$ const, has been shown in Fig. 4 .

\section{CALCULATIONS OF FATIGUE PERSISTENCE}

In Table 2, which has a similar arrangement as Table 1, in the respective fields, number of cycles for fatigue crack $N_{i j}$ calculated from the formulas (7) to (10) depending on the value $S_{a i}$ and $S_{m j}$, were specified.

From the data in Tables 1 and 2 and the formula (4) one may firstly calculate the value of ratios $\alpha_{i j} / N_{i j}$ in each field, and then the sum of the damage and and fatigue persistence and its number of cycles $n_{c}$.

for $-1 \leq R \leq 1$

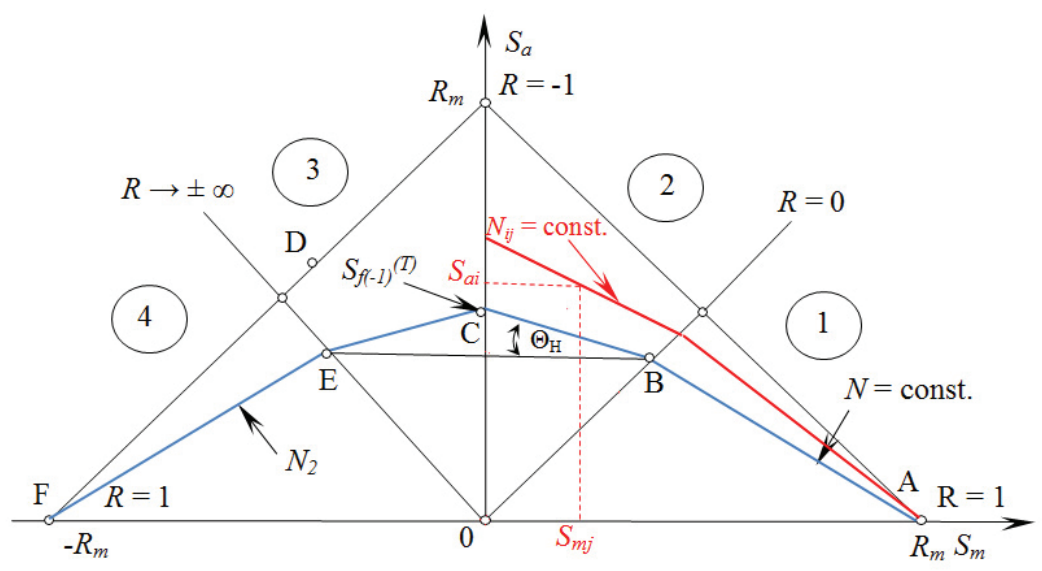

Fig. 4. A diagram of two-parameter characteristics of fatigue in the schematic view 
Tab. 2. Numbers of cycles $N_{i j}-S_{\max }=160 \mathrm{MPa}$

\begin{tabular}{|c|c|c|c|c|c|c|c|c|c|}
\hline \multirow{2}{*}{\multicolumn{2}{|c|}{$S_{m j} S^{i} S_{i i}$}} & 128 & 112 & 96 & 80 & 64 & 48 & 32 & 16 \\
\hline & & 1 & 2 & 3 & 4 & 5 & 6 & 7 & 8 \\
\hline 64 & 1 & & & & & $9,5 \cdot 10^{6}$ & & $2,5 \cdot 10^{8}$ & \\
\hline 48 & 2 & & & & & $1,0 \cdot 10^{7}$ & $7,0 \cdot 10^{7}$ & $2,5 \cdot 10^{8}$ & $7,0 \cdot 10^{8}$ \\
\hline 32 & 3 & $8,5 \cdot 10^{5}$ & & $2,5 \cdot 10^{6}$ & $4,5 \cdot 10^{6}$ & $1,5 \cdot 10^{7}$ & $7,5 \cdot 10^{7}$ & $2,5 \cdot 10^{8}$ & \\
\hline 16 & 4 & & $2,5 \cdot 10^{6}$ & $5,0 \cdot 10^{6}$ & $7,5 \cdot 10^{6}$ & $2,5 \cdot 10^{7}$ & $7,5 \cdot 10^{7}$ & $2,5 \cdot 10^{8}$ & $7,0 \cdot 10^{8}$ \\
\hline 0 & 5 & & & $5,2 \cdot 10^{6}$ & $8,0 \cdot 10^{6}$ & $2,0 \cdot 10^{7}$ & $7,5 \cdot 10^{7}$ & $2,5 \cdot 10^{8}$ & $7,0 \cdot 10^{8}$ \\
\hline $\begin{array}{c}- \\
16 \\
\end{array}$ & 6 & $9,0 \cdot 10^{5}$ & & $5,0 \cdot 10^{6}$ & & $2,5 \cdot 10^{7}$ & $7,5 \cdot 10^{7}$ & $2,5 \cdot 10^{8}$ & $7,0 \cdot 10^{8}$ \\
\hline $\begin{array}{c}- \\
32 \\
\end{array}$ & 7 & & & & & $1,5 \cdot 10^{7}$ & $7,5 \cdot 10^{7}$ & $2,5 \cdot 10^{8}$ & $7,0 \cdot 10^{8}$ \\
\hline $\begin{array}{c}- \\
48\end{array}$ & 8 & & & & & & $7,0 \cdot 10^{7}$ & $2,5 \cdot 10^{8}$ & $7,0 \cdot 10^{8}$ \\
\hline $\begin{array}{c}- \\
64\end{array}$ & 9 & & & & & & & & \\
\hline
\end{tabular}

$S_{\max }=200 \mathrm{MPa}$

\begin{tabular}{|c|c|c|c|c|c|c|c|c|c|}
\hline \multirow{2}{*}{\multicolumn{2}{|c|}{$S_{m j} j^{i}$}} & 160 & 140 & 120 & 100 & 80 & 60 & 40 & 20 \\
\hline & & 1 & 2 & 3 & 4 & 5 & 6 & 7 & 8 \\
\hline 80 & 1 & & & & & $5,5 \cdot 10^{6}$ & & $8,5 \cdot 10^{7}$ & \\
\hline 60 & 2 & & & & & $6,0 \cdot 10^{6}$ & $1,5 \cdot 10^{7}$ & $9,5 \cdot 10^{7}$ & $3,5 \cdot 10^{8}$ \\
\hline 40 & 3 & $4,0 \cdot 10^{5}$ & & $9,0 \cdot 10^{5}$ & $2,5 \cdot 10^{6}$ & $6,5 \cdot 10^{6}$ & $2,0 \cdot 10^{7}$ & $1,0 \cdot 10^{8}$ & \\
\hline 20 & 4 & & $7,5 \cdot 10^{5}$ & $9,5 \cdot 10^{5}$ & $3,0 \cdot 10^{6}$ & $7,0 \cdot 10^{6}$ & $2,5 \cdot 10^{7}$ & $1,0 \cdot 10^{8}$ & $5,0 \cdot 10^{8}$ \\
\hline 0 & 5 & & & $1,0 \cdot 10^{6}$ & $4,5 \cdot 10^{6}$ & $8,0 \cdot 10^{6}$ & $3,0 \cdot 10^{7}$ & $1,0 \cdot 10^{8}$ & $5,0 \cdot 10^{8}$ \\
\hline-20 & 6 & $5,0 \cdot 10^{5}$ & & $9,5 \cdot 10^{5}$ & & $7,0 \cdot 10^{6}$ & $2,5 \cdot 10^{7}$ & $1,0 \cdot 10^{8}$ & $5,0 \cdot 10^{8}$ \\
\hline-40 & 7 & & & & & $6,5 \cdot 10^{6}$ & $2,0 \cdot 10^{7}$ & $1,0 \cdot 10^{8}$ & $4,0 \cdot 10^{8}$ \\
\hline-60 & 8 & & & & & & $1,5 \cdot 10^{7}$ & $9,5 \cdot 10^{7}$ & $3,5 \cdot 10^{8}$ \\
\hline-80 & 9 & & & & & & & & \\
\hline
\end{tabular}

$S_{\max }=240 \mathrm{MPa}$

\begin{tabular}{|c|c|c|c|c|c|c|c|c|c|}
\hline \multirow{2}{*}{\multicolumn{2}{|c|}{$S_{m j}{ }^{i} S_{a i}$}} & 192 & 168 & 144 & 120 & 96 & 72 & 48 & 24 \\
\hline & & 1 & 2 & 3 & 4 & 5 & 6 & 7 & 8 \\
\hline 96 & 1 & & & & & $1,0 \cdot 10^{6}$ & & $4,5 \cdot 10^{7}$ & \\
\hline 72 & 2 & & & & & $1,5 \cdot 10^{6}$ & $7,5 \cdot 10^{6}$ & $6,0 \cdot 10^{7}$ & $2,0 \cdot 10^{8}$ \\
\hline 48 & 3 & $0,1 \cdot 10^{5}$ & & $5,5 \cdot 10^{5}$ & $9,0 \cdot 10^{5}$ & $2,5 \cdot 10^{6}$ & $8,5 \cdot 10^{6}$ & $7,0 \cdot 10^{7}$ & \\
\hline 24 & 4 & & $3,0 \cdot 10^{5}$ & $6,0 \cdot 10^{5}$ & $9,5 \cdot 10^{5}$ & $4,5 \cdot 10^{6}$ & $8,5 \cdot 10^{6}$ & $7,5 \cdot 10^{7}$ & $4,5 \cdot 10^{8}$ \\
\hline 0 & 5 & & & $7,5 \cdot 10^{5}$ & $1,0 \cdot 10^{6}$ & $5,0 \cdot 10^{6}$ & $9,5 \cdot 10^{6}$ & $7,5 \cdot 10^{7}$ & $4,0 \cdot 10^{8}$ \\
\hline-24 & 6 & $1,5 \cdot 10^{5}$ & & $6,0 \cdot 10^{5}$ & & $4,5 \cdot 10^{6}$ & $8,5 \cdot 10^{6}$ & $7,5 \cdot 10^{7}$ & $4,5 \cdot 10^{8}$ \\
\hline-48 & 7 & & & & & $2,5 \cdot 10^{6}$ & $8,5 \cdot 10^{6}$ & $7,0 \cdot 10^{7}$ & $2,5 \cdot 10^{8}$ \\
\hline-72 & 8 & & & & & & $7,5 \cdot 10^{6}$ & $6,0 \cdot 10^{7}$ & $2,0 \cdot 10^{8}$ \\
\hline-96 & 9 & & & & & & & & \\
\hline
\end{tabular}

Tab. 3: Ratio values $\alpha_{i j} / N_{i j}$ for: a) $\left.S_{\max }=160 \mathrm{MPa}, b\right) S_{\max }=200 \mathrm{MPa}$, c) $S_{\text {max }}=240 \mathrm{MPa}$

a)

\begin{tabular}{|c|c|c|c|c|c|c|c|c|c|}
\hline \multirow{2}{*}{\multicolumn{2}{|c|}{$j \mid i$}} & 0,8 & 0,7 & 0,6 & 0,5 & 0,4 & 0,3 & 0,2 & 0,1 \\
\hline & & 1 & 2 & 3 & 4 & 5 & 6 & 7 & 8 \\
\hline 0,4 & 1 & & & & & $0,45 \cdot 10^{-9}$ & & $8,66 \cdot 10^{-11}$ & \\
\hline 0,3 & 2 & & & & & $8,66 \cdot 10^{-10}$ & $1,23 \cdot 10^{-10}$ & $26 \cdot 10^{-11}$ & $6,8 \cdot 10^{-11}$ \\
\hline 0,2 & 3 & $1,01 \cdot 10^{-8}$ & & $1,73 \cdot 10^{-9}$ & $0,96 \cdot 10^{-9}$ & $2,88 \cdot 10^{-10}$ & $6,34 \cdot 10^{-10}$ & $36,36 \cdot 10^{-11}$ & \\
\hline 0,1 & 4 & & $5,2 \cdot 10^{-9}$ & $3,46 \cdot 10^{-9}$ & $4,04 \cdot 10^{-9}$ & $13,8 \cdot 10^{-10}$ & $2,3 \cdot 10^{-10}$ & $26 \cdot 10^{-11}$ & $6,8 \cdot 10^{-11}$ \\
\hline 0 & 5 & & & $1,66 \cdot 10^{-9}$ & $4,32 \cdot 10^{-9}$ & $13,0 \cdot 10^{-10}$ & $2,88 \cdot 10^{-10}$ & $36,36 \cdot 10^{-11}$ & $3,09 \cdot 10^{-11}$ \\
\hline$-0,1$ & 6 & $0,48 \cdot 10^{-8}$ & & $0,86 \cdot 10^{-9}$ & & $3,46 \cdot 10^{-10}$ & $1,15 \cdot 10^{-10}$ & $22,51 \cdot 10^{-11}$ & $3,71 \cdot 10^{-11}$ \\
\hline$-0,2$ & 7 & & & & & $2,88 \cdot 10^{-10}$ & $1,15 \cdot 10^{-10}$ & $10,4 \cdot 10^{-11}$ & $3,09 \cdot 10^{-11}$ \\
\hline$-0,3$ & 8 & & & & & & $1,23 \cdot 10^{-10}$ & $5,2 \cdot 10^{-11}$ & $3,09 \cdot 10^{-11}$ \\
\hline$-0,4$ & 9 & & & & & & & & \\
\hline
\end{tabular}


b)

\begin{tabular}{|c|c|c|c|c|c|c|c|c|c|}
\hline \multicolumn{2}{|c|}{$j \mid i$} & 0,8 & 0,7 & 0,6 & 0,5 & 0,4 & 0,3 & 0,2 & 0,1 \\
\hline & 1 & 2 & 3 & 4 & 5 & 6 & 7 & 8 \\
\hline 0,4 & 1 & & & & & $0,78 \cdot 10^{-9}$ & & $2,54 \cdot 10^{-10}$ & \\
\hline 0,3 & 2 & & & & & $1,44 \cdot 10^{-9}$ & $5,77 \cdot 10^{-10}$ & $6,84 \cdot 10^{-10}$ & $13,6 \cdot 10^{-11}$ \\
\hline 0,2 & 3 & $2,16 \cdot 10^{-8}$ & & $0,48 \cdot 10^{-8}$ & $1,73 \cdot 10^{-9}$ & $0,66 \cdot 10^{-9}$ & $23,8 \cdot 10^{-10}$ & $90,91 \cdot 10^{-11}$ & \\
\hline 0,1 & 4 & & $1,73 \cdot 10^{-8}$ & $1,82 \cdot 10^{-8}$ & $10,1 \cdot 10^{-9}$ & $4,94 \cdot 10^{-9}$ & $6,92 \cdot 10^{-10}$ & $65 \cdot 10^{-11}$ & $9,52 \cdot 10^{-11}$ \\
\hline 0 & 5 & & & $8,66 \cdot 10^{-9}$ & $7,69 \cdot 10^{-9}$ & $3,25 \cdot 10^{-9}$ & $7,21 \cdot 10^{-10}$ & $90,91 \cdot 10^{-11}$ & $4,33 \cdot 10^{-11}$ \\
\hline$-0,1$ & 6 & $0,86 \cdot 10^{-8}$ & & $0,45 \cdot 10^{-8}$ & & $1,23 \cdot 10^{-9}$ & $3,46 \cdot 10^{-10}$ & $56,28 \cdot 10^{-11}$ & $5,2 \cdot 10^{-11}$ \\
\hline$-0,2$ & 7 & & & & & $0,66 \cdot 10^{-9}$ & $4,33 \cdot 10^{-10}$ & $26 \cdot 10^{-11}$ & $5,41 \cdot 10^{-11}$ \\
\hline$-0,3$ & 8 & & & & & & $5,77 \cdot 10^{-10}$ & $1,36 \cdot 10^{-10}$ & $6,18 \cdot 10^{-11}$ \\
\hline$-0,4$ & 9 & & & & & & & & \\
\end{tabular}

c)

\begin{tabular}{|c|c|c|c|c|c|c|c|c|c|}
\hline \multicolumn{2}{|c|}{$j \mid i$} & 0,8 & 0,7 & 0,6 & 0,5 & 0,4 & 0,3 & 0,2 & 0,1 \\
\cline { 3 - 10 } & 1 & 2 & 3 & 4 & 5 & 6 & 7 & 8 \\
\hline 0,4 & 1 & & & & & $4,33 \cdot 10^{-9}$ & & $4,81 \cdot 10^{-10}$ & \\
\hline 0,3 & 2 & & & & & $5,77 \cdot 10^{-9}$ & $1,15 \cdot 10^{-9}$ & $10,81 \cdot 10^{-10}$ & $23,81 \cdot 10^{-11}$ \\
\hline 0,2 & 3 & $8,66 \cdot 10^{-8}$ & & $0,78 \cdot 10^{-8}$ & $0,48 \cdot 10^{-8}$ & $1,73 \cdot 10^{-9}$ & $5,6 \cdot 10^{-9}$ & $12,98 \cdot 10^{-10}$ & \\
\hline 0,1 & 4 & & $4,33 \cdot 10^{-8}$ & $2,88 \cdot 10^{-8}$ & $3,18 \cdot 10^{-8}$ & $7,69 \cdot 10^{-9}$ & $2,03 \cdot 10^{-9}$ & $8,66 \cdot 10^{-10}$ & $10,58 \cdot 10^{-11}$ \\
\hline 0 & 5 & & & $1,15 \cdot 10^{-8}$ & $34,6 \cdot 10^{-9}$ & $5,2 \cdot 10^{-9}$ & $2,27 \cdot 10^{-9}$ & $12,12 \cdot 10^{-10}$ & $5,41 \cdot 10^{-11}$ \\
\hline$-0,1$ & 6 & $2,88 \cdot 10^{-8}$ & & $0,72 \cdot 10^{-8}$ & & $1,92 \cdot 10^{-9}$ & $1,01 \cdot 10^{-9}$ & $7,5 \cdot 10^{-10}$ & $5,77 \cdot 10^{-11}$ \\
\hline$-0,2$ & 7 & & & & & $1,73 \cdot 10^{-9}$ & $1,01 \cdot 10^{-9}$ & $3,71 \cdot 10^{-10}$ & $8,66 \cdot 10^{-11}$ \\
\hline$-0,3$ & 8 & & & & & & $1,15 \cdot 10^{-9}$ & $2,16 \cdot 10^{-10}$ & $10,82 \cdot 10^{-11}$ \\
\hline$-0,4$ & 9 & & & & & & & & \\
\hline
\end{tabular}

Ratio figures $\alpha_{i j} / N_{i j}$ were summarized in Table 3 and the results of calculation of the fatigue persistence $n_{c}$ according to formula (4) are shown in Table 4. The persistence chart has been shown in Fig. 5 according to the description provided in the form of a mathematical model (12).

Table 4: The results of calculation of fatigue persistence of the soldered construction node

\begin{tabular}{|c|c|c|c|}
\hline$S_{\max }[\mathrm{MPa}]$ & 160 & 200 & 240 \\
\hline$n_{c}$ & $2,19 \cdot 10^{7}$ & $7,89 \cdot 10^{6}$ & $8,18 \cdot 10^{5}$ \\
\hline
\end{tabular}

$$
\log S_{\max }=-0,1242 \log n_{c}+3,1394
$$

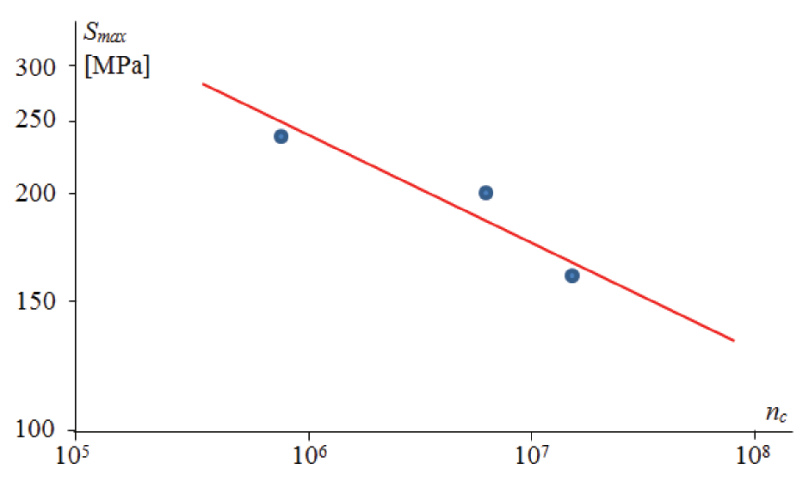

Fig. 5. Fatigue persistence chart according to data from Table 4.

\section{RESEARCH ON FATIGUE PERSISTENCE OF THE CONSTRUCTION ELEMENT}

The studies of fatigue persistence of the construction element were performed with the use of programmable research method. The load program in the fatigue tests corresponded to the load of the calculation described in section 4. Results of programmable studies were summarized in Table 5, and the fatigue persistence chart has been shown in Fig. 6.
Tab. 5: Results of fatigue persistence studies $n_{c}^{E x}$

\begin{tabular}{|c|c|c|c|c|c|c|}
\hline$S_{\text {amax }}$ & \multicolumn{5}{|c|}{$n_{c}^{E x}$} \\
\hline$[\mathrm{MPa}]$ & 1 & 2 & 3 & 4 & 5 & 6 \\
\hline 240 & $5,8 \cdot 10^{5}$ & $1,36 \cdot 10^{6}$ & $2,05 \cdot 10^{6}$ & $9,15 \cdot 10^{5}$ & $9,86 \cdot 10^{5}$ & $2,43 \cdot 10^{6}$ \\
\hline 200 & $2,62 \cdot 10^{6}$ & $4,23 \cdot 10^{6}$ & $6,13 \cdot 10^{6}$ & $5,13 \cdot 10^{6}$ & $8,95 \cdot 10^{6}$ & $1,45 \cdot 10^{7}$ \\
\hline 160 & $1,83 \cdot 10^{7}$ & $2,79 \cdot 10^{7}$ & $8,52 \cdot 10^{7}$ & $1,15 \cdot 10^{7}$ & $2,41 \cdot 10^{7}$ & $5,8 \cdot 10^{7}$ \\
\hline 120 & $8,95 \cdot 10^{7}$ & $2,15 \cdot 10^{8}$ & $3,45 \cdot 10^{8}$ & $1,52 \cdot 10^{8}$ & $2,75 \cdot 10^{8}$ & $5,34 \cdot 10^{8}$ \\
\hline
\end{tabular}

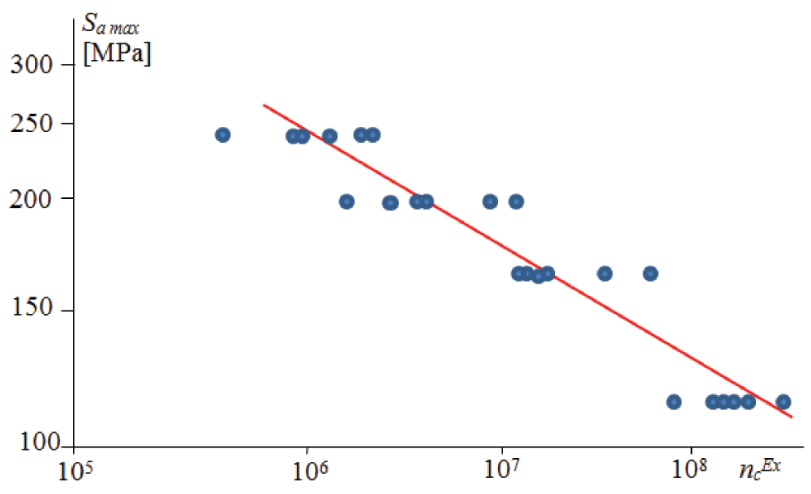

Fig. 6. Chart of fatigue persistence i terms of programmable load

The chart of fatigue persistence determined based on the experimental data described by the formula (13).

$$
\log S_{\text {max }}=-0,1227 \log n_{c}+3,1219
$$

\section{COMPARATIVE ANAYSIS OF TEST RESULTS AND CALCULATION AND CONCLUSIONS}

A comparison of formulas (12) and (13) shows a significant compliance of fatigue persistence determined experimentally according to the results of the calculation methods described in point 2 of this work. The compliance is the result of carefully selected methods to develop a load program, two-parameter characteristics of fatigue and summation hypotheses of fatigue damage. 
For loads of a broad spectrum, adopting the method of counting complete cycles proved to be appropriate and in line with the general recommendations in this area [8]. Similarly, the adoption of two-parameter characterization of fatigue IM [13] verified experimentally for construction steel favoured the compatibility of the calculation of the test results. Basing calculations on the load spectrum in the form of a table of correlation [5] and two-parameter characterization of fatigue avoided the reduction of asymmetric cycles to symmetric cycles $(R=-1,0)$ which is associated with considerable simplifications affecting the accuracy of the calculations.

Relative positions of the graphs of the fatigue persistence determined by means of calculations and experimental tests are shown in Fig. 7. The relative differences in the stability of the graphs calculated extremities are:

$$
\begin{aligned}
& \text { - for } S_{\text {max }}=150 \mathrm{MP} \\
& \delta=\frac{n_{c o b l}-n_{c e x}}{n_{c o b l}}=\frac{5,7892 \cdot 10^{7}-5,1082 \cdot 10^{7}}{5,7892 \cdot 10^{7}}=0,1176
\end{aligned}
$$

- for $S_{\max }=300 \mathrm{MPa}$

$$
\delta=\frac{n_{c o b l}-n_{c e x}}{n_{c o b l}}=\frac{2,1454 \cdot 10^{5}-1,7994 \cdot 10^{5}}{2,1454 \cdot 10^{5}}=0,1612
$$

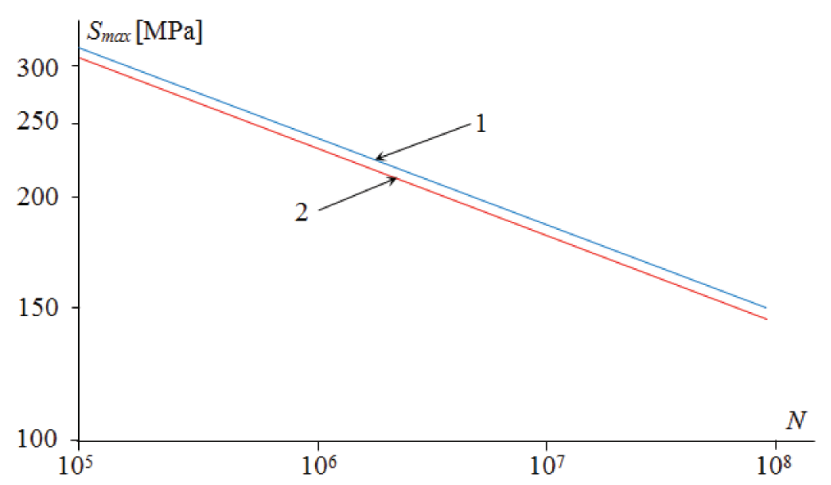

Fig. 7. The relative position of persistence charts: 1 - as determined by the calculation method, 2 - as determined by programmable testing method

From the above calculations, the formulas (14) and (15) show that the relative differences in results determined by the stability calculation and programmed methods are respectively: for $S_{\max }=150 \mathrm{MPa}-11,76 \%$, for $S_{\max }=300 \mathrm{MPa}-$ $16,12 \%$. Taking into account the natural considerable dispersion of results of fatigue tests, especially soldered construction elements, these differences are insignificant.

The above analysis shows that in the case of structural components made of steel, subject to the conditions of random service loads of a broad spectrum, an appropriate method of calculation of the fatigue persistence is the method of application in the filed:
- development of load spectra method of counting complete cycles or envelope method,

- selection of fatigue characteristics - the adoption of two-parameters characterstics of fatigue IM according to [13],

- summation hypothesis of fatigue damage- the adoption of the linear hypothesis of fatigue damage summation by Palmgren-Miner.

\section{BIBLIOGRAPHY}

1. LIGAJ B., SZALA G.: Experimental verification of twoparameters models of fatigue characteristics by using the tests of S55J0 steel as an example, Polish Maritime Research, 1(63) 2010, Vol. 17 pp.39-50

2. API: Recommended Practice for Planning, Designing and Constructing, Fixed Offshore Platforms - Loads and Resistance Factor Design, American Petroleum Institute, Washington DC, 1993

3. FRICKE W., PETERSHAGEN H., PAETZOLD H.: Fatigue Strength of Ship Structures - Part I: Basic Principles, published by Germanischer Lloyd and Institute of Naval Architecture of the Hamburg University, Hamburg, 1997

4. FRICKE W., PETERSHAGEN H., PAETZOLD H.: Fatigue Strength of Ship Structures - Part II: Examples, published by Germanischer Lloyd and Institute of Naval Architecture of the Hamburg University, Hamburg, 1998

5. LIGAJ B.: The influence of loadings programes elaborated on the base on correlation chart steel 18G2A fatigue live, Problemy Eksploatacji - Zeszyty Naukowe 3/2007 (66), str. 129-146

6. SZALA J.: Hipotezy sumowania uszkodzeń zmęczeniowych, Wydawnictwo Uczelniane Akademii Techniczno-Rolniczej, Bydgoszcz, 1998

7. ASTM: Standard Practises for Cycle Counting in Fatigue Analysis, ASTM Designation E 1049-85, American Society for Testing and Materials, New York

8. KOCAŃDA S., SZALA J.: Podstawy obliczeń zmęczeniowych, Wydanie III, Wydawnictwa Naukowe PWN, Warszawa, 1997

9. KOZAK J.: Selected problems on application of steel sandwich panels to marine structures, Polish Maritime Research, 4(62) 2009, Vol. 16, 2009

10. KOZAK J.: Fatigue life of steel laser - welded panels, Polish Maritime Research, Special Issue S1, 2006 
11. HOBBACHER A.: Recommendations for fatigue design of welded joins and components, IIW document XIII-196503/XV-1127-3, 2004

12. JANOSCH J.-J.: FITNET MK7 (European Fitness for Service Network), Section 7, Fatigue Module, Caterpillar, France, 2006

13. SZALA G.: The modification of the generalized twoparametric fatigue characteristics based on High diagram conception. Scientific Problems of Machines Operation and Maintenance nr 2/2010, Radom, 2010

\section{CONTACT WITH THE AUTHOR}

Grzegorz Szala

University of Science and Technology in Bydgoszcz

Al. Prof. S. Kaliskiego 7

85-796 Bydgoszcz

\section{Poland}

